\title{
Meta-analysis of Guided Bronchoscopy for the Evaluation of the Pulmonary Nodule
}

\author{
Jessica S. Wang Memoli, MD; Paul J. Nietert, PhD; and Gerard A. Silvestri, MD, FCCP
}

\begin{abstract}
Background: The detection of pulmonary nodules (PNs) is likely to increase, especially with the release of the National Lung Screen Trials. When tissue diagnosis is desired, transthoracic needle aspiration (TTNA) is recommended. Several guided-bronchoscopy technologies have been developed to improve the yield of transbronchial biopsy for PN diagnosis: electromagnetic navigation bronchoscopy (ENB), virtual bronchoscopy (VB), radial endobronchial ultrasound (R-EBUS), ultrathin bronchoscope, and guide sheath. We undertook this meta-analysis to determine the overall diagnostic yield of guided bronchoscopy using one or a combination of the modalities described here.

Methods: We performed a MEDLINE search using "bronchoscopy" and "solitary pulmonary nodule." Studies evaluating the diagnostic yield of ENB, VB, R-EBUS, ultrathin bronchoscope, and/or guide sheath for peripheral nodules were included. The overall diagnostic yield and yield based on size were extracted. Adverse events, if reported, were recorded. Meta-analysis techniques incorporating inverse variance weighting and a random-effects meta-analysis approach were used.

Results: A total of 3,052 lesions from 39 studies were included. The pooled diagnostic yield was 70\%, which is higher than the yield for traditional transbronchial biopsy. The yield increased as the lesion size increased. The pneumothorax rate was $1.5 \%$, which is significantly smaller than that reported for TTNA.

Conclusion: This meta-analysis shows that the diagnostic yield of guided bronchoscopic techniques is better than that of traditional transbronchial biopsy. Although the yield remains lower than that of TTNA, the procedural risk is lower. Guided bronchoscopy may be an alternative or be complementary to TTNA for tissue sampling of PN, but further study is needed to determine its role in the evaluation of peripheral pulmonary lesions.

CHEST 2012; 142(2):385-393
\end{abstract}

Abbreviations: $\mathrm{ENB}=$ electromagnetic navigation bronchoscopy; NLST = National Lung Screening Trial; PN = pulmonary nodule; R-EBUS = radial endobronchial ultrasound; TTNA = transthoracic needle aspiration; $\mathrm{VB}=$ virtual bronchoscopy

$\mathbf{T}^{\mathrm{i}}$ he pulmonary nodule $(\mathrm{PN})$ is becoming an increasingly common radiographic finding among patients in the United States. Nearly 45 million CT scan examinations are performed each year, and $11 \%$ to $30 \%$ (4.5-14 million) of those include an examination of

Manuscript received July 20, 2011; revision accepted September 1, 2011.

Affiliations: From the Section of Pulmonary, Critical Care, and Respiratory Services (Dr Wang Memoli), Washington Hospital Center, Washington, DC; and the Division of Biostatistics and Epidemiology (Dr Nietert) and the Division of Pulmonary, Critical Care, Allergy and Sleep Medicine (Dr Silvestri), Medical University of South Carolina, Charleston, SC.

Funding/Support: This publication was supported by the South Carolina Clinical and Translational Research Institute, Medical University of South Carolina's Clinical Translational Science Award, and the National Institutes of Health/National Center for Research Resources [Grant UL1RR029882].

Correspondence to: Jessica S. Wang Memoli, MD, 110 Irving S NW, 2A-68, Washington, DC 20010; e-mail: Jessica.S.WangMemoli@ Medstar.net the chest. ${ }^{1}$ In the recently released National Cancer Institute-sponsored National Lung Screening Trial (NLST), $>25 \%$ of the group who underwent lowdose CT scans of the chest had examinations that were

\section{For editorial comment see page 276 For related article see page 377}

suspicious for lung cancer. ${ }^{2}$ With the findings of the NLST indicating a reduction in lung-cancer-specific mortality with CT scanning in at-risk people, the number of patients diagnosed with a PN could increase substantially if screening for lung cancer is broadly

(C) 2012 American College of Chest Physicians. Reproduction of this article is prohibited without written permission from the American College of Chest Physicians. See online for more details. DOI: $10.1378 /$ chest.11-1764 
accepted by the medical community. The prevalence of malignancy in studies evaluating patients with noncalcified nodules ranges from $2 \%$ to $82 \%,{ }^{3}$ and health-care providers are often faced with the diagnostic dilemma of how to manage these patients. The goal is to diagnose malignant nodules promptly, to permit timely surgical resection, while avoiding invasive testing or surgery in patients with benign nodules.

Practice guidelines offer recommendations for the diagnosis and management of the PN. ${ }^{4}$ The three general management categories based on the patient's probability of malignancy are watchful waiting with serial CT scans, tissue biopsy for pathologic diagnosis, and direct surgical excision. When biopsy is recommended, transthoracic needle aspiration (TTNA) is currently preferred because it has a diagnostic yield of 90\%; however, TTNA also has a pneumothorax rate of about $25 \%$, of which at least $15 \%$ requires chest tube insertion (overall chest tube rate of $5 \%$ )., 4,5 Flexible bronchoscopy is another diagnostic option, but the sensitivity of traditional transbronchial biopsy ranges from $14 \%$ to $63 \%$, depending on the size and location of the PN. ${ }^{5,6}$ Bronchoscopy with guidance has evolved as a viable option "if the operator has expertise in newer guided techniques." 4

Within the past decade, new techniques have emerged that offer guidance through the tracheobronchial tree during bronchoscopy to help reach and biopsy PN. Electromagnetic navigation bronchoscopy (ENB) and virtual bronchoscopy (VB) are able to create a virtual bronchoscopic image and a pathway to the PN (Fig 1). ENB can give additional real-time directions to the $\mathrm{PN}$, much like a car's global positioning system for driving to a destination. Using an ultrathin bronchoscope combined with radial endobronchial ultrasound (R-EBUS) through a guide sheath allows the practitioner to visualize the sixth- to eighth-generation bronchi (whereas a traditional bronchoscope can only reach the fourthgeneration bronchi), verify that the lesion has been reached, and maintain the position in the periphery for biopsy.

A number of studies have been published using a variety of these technologies to guide the bronchoscopist to the nodule for biopsy. Most have been small, single-institution case series that reported the diagnostic accuracy of the new technology being investigated. We undertook this meta-analysis to assess the overall diagnostic yield and adverse event rate of these technologies in studies that evaluated any one or a combination of these guidance mechanisms for the tissue biopsy of peripheral lung lesions and to compare and contrast these findings with the reported diagnostic yields of traditional bronchoscopy and TTNA.

\section{Materials AND METHODS}

\section{Data Sources}

An Ovid MEDLINE (1950 through October 2010) and PubMed database search was performed using "bronchoscopy" and "pulmonary nodule" as terms to identify studies. The search was limited to human subjects. Although the search was not limited to English language studies, no non-English language studies met the inclusion criteria. The reference lists of included studies and review articles were searched manually for other relevant studies.

\section{Study Selection}

Review articles and commentaries were excluded from the meta-analysis, but the manuscript and the reference lists of relevant review articles were examined to find other studies. Both prospective and retrospective studies were evaluated for inclusion. The remaining studies were reviewed for relevance. All studies that reported the use of any of the following technologies to evaluate PN were considered for inclusion: ENB or superDimension, VB, endobronchial ultrasound (specifically R-EBUS), ultrathin bronchoscope, and guide sheath. All included studies documented the diagnostic yield of guided bronchoscopy using one or more of the methods described here. Case reports and studies with fewer than five patients were excluded. Studies were excluded if the linear endobronchial ultrasound was used instead of R-EBUS or if guidance was performed with CT scan-fluoroscopy alone. Studies that were performed on inanimate models or on patients without radiographic evidence of nodules to evaluate feasibility were excluded.

\section{Data Synthesis}

The articles were reviewed by two investigators (J. W. M. and G. S.). Many of the studies were pilot or feasibility studies undertaken to determine the diagnostic yield of a new technology. The primary technology used and the addition of other methods (eg, VB with R-EBUS) were recorded. The number of lesions and the number of diagnoses made were extracted. The overall diagnostic yield was calculated from the extracted data and compared with the reported diagnostic yield. Although the majority of diagnoses were malignant (primary lung or metastatic disease), other benign causes of the PN (eg, TB, sarcoidosis) were also considered diagnostic if found. If reported in the study, the yield by size $(>20 \mathrm{~mm}$ or $\leq 20 \mathrm{~mm}$ ) was recorded. The type of study (prospective vs retrospective) was recorded. All adverse events of pneumothorax, respiratory failure, and severe hemorrhage were extracted if reported.

\section{Statistical Analysis}

The reported diagnostic yield proportions from each study were aggregated via meta-analysis techniques that incorporated an inverse variance weighting technique and allowed us (via the $Q$ statistic) to determine whether there was significant between-study variation (heterogeneity). ${ }^{7}$ We also used a random-effects meta-analysis approach that yielded similar findings (results not presented). These processes account for the study sample size and study heterogeneity. Inverse-variance weighted means of the studies' diagnostic yields and their 95\% CIs were computed across all studies. Studies that used a specific method of biopsy were grouped (ie, all studies that used VB were grouped even if a combination of technologies was evaluated in an individual study), and the same computations for inverse variance weighted means were performed for each group. Because diagnostic yield for study $i$ is 


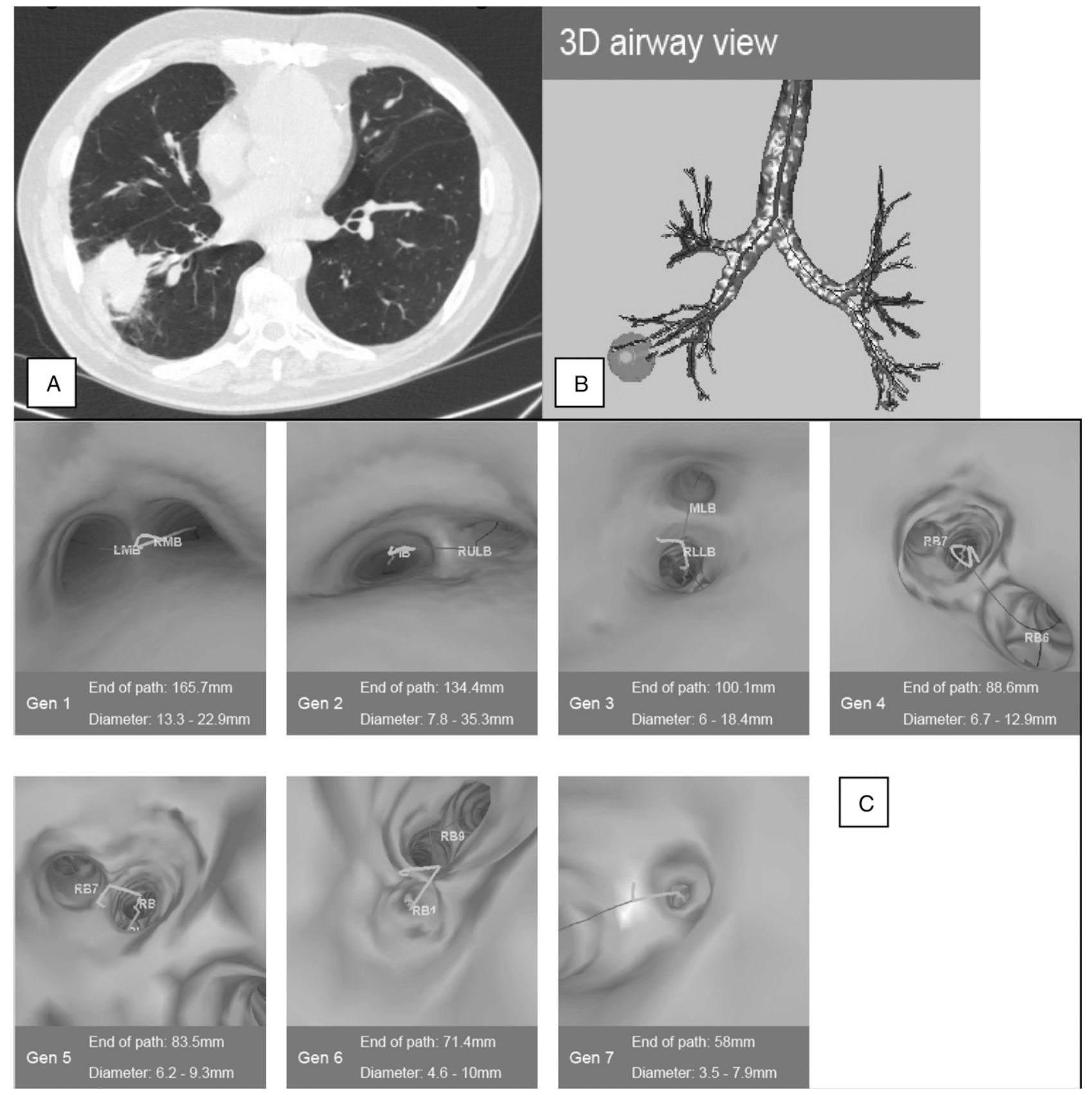

Figure 1. A, Chest CT image of a right lower lobe pulmonary lesion in a 78-year-old smoker. B, 3-D reconstruction of the tracheobronchial tree with the nodule outlined. C, Airway reconstruction of the pathway to the peripheral lesion. (Figure created and provided by Broncus Technologies, Inc.) Gen = generation; $\mathrm{LMB}=$ left mainstem bronchus; $\mathrm{MLB}=$ middle lobe bronchus; $\mathrm{RB}=$ right bronchial; $\mathrm{RLLB}=$ right lower lobe bronchus; $\mathrm{RMB}=$ right mainstem bronchus; RULB = right upper lobe bronchus.

a percentage $\left(\operatorname{Yield}_{i}\right)$ out of the study sample size $\left(n_{i}\right)$, its variance is simply

$$
\sigma_{i}^{2}=\frac{\text { Yield }_{i} \times\left(1-\text { Yield }_{i}\right)}{n_{i}}
$$

using standard binomial theory. ${ }^{8}$ The reciprocal of this variance measure

$$
w_{i}=\frac{1}{\sigma_{i}^{2}}
$$

served as a weight within the calculation of the weighted mean diagnostic yield for this meta-analysis:

$$
\text { Inverse variance weighted diagnostic yield }=\frac{\sum_{i=1}^{N} w_{i} \times \text { Yield }_{i}}{\sum_{i=1}^{N} w_{i}}
$$

where $N$ reflects the total number of eligible studies. 


\section{Results}

The MEDLINE and PubMed searches identified 140 and 309 potential studies, respectively. A thorough review of the reference lists of related studies uncovered an additional 29 studies. From these, a total of 39 studies met the inclusion criteria and were included in the analysis (Fig 2). The included studies were published between 2002 and October 2010. All studies reported the diagnostic yield of bronchoscopic biopsy of PN using at least one of five guidance techniques: VB, ENB, R-EBUS, guide sheath, or ultrathin bronchoscope. Six of the studies were retrospective. A total of 3,004 patients with 3,052 lesions from the 39 studies were included in this meta-analysis. Table $1^{9-47}$ lists the study characteristics and summarizes the findings for each of the studies (Fig 3).

The inverse variance weighted diagnostic yield was $70.0 \%$ with a $95 \%$ CI of $67.1 \%$ to $72.9 \%$ (Table 2). Across the studies, the diagnostic yield ranged from $46.0 \%$ to $86.2 \%$ (Fig 2), and the Q statistic $\left(\chi_{[30 \mathrm{df}]}^{2}=119.4\right)$ indicated that there was significant $(P<.0001)$ variation in the diagnostic yield estimates. Table 2 lists the pooled diagnostic yield estimates for groups of studies that used various technologies, along with group-specific heterogeneity test results. Diagnostic yield appeared to be highest $(73.2 \%$ [95\% CI, $64.4 \%$ to $81.9 \%$ ]) when a guide sheath was used, although there was significant variation across studies $(\mathrm{Q}$ statistic $=63.8, P<.0001)$. The yields for VB (72.0\% [95\% CI, $65.7 \%$ to $78.4 \%$ ]) and R-EBUS $(71.1 \%$ [95\% CI, $66.5 \%$ to $75.7 \%)$ were also higher than the overall weighted diagnostic yield.

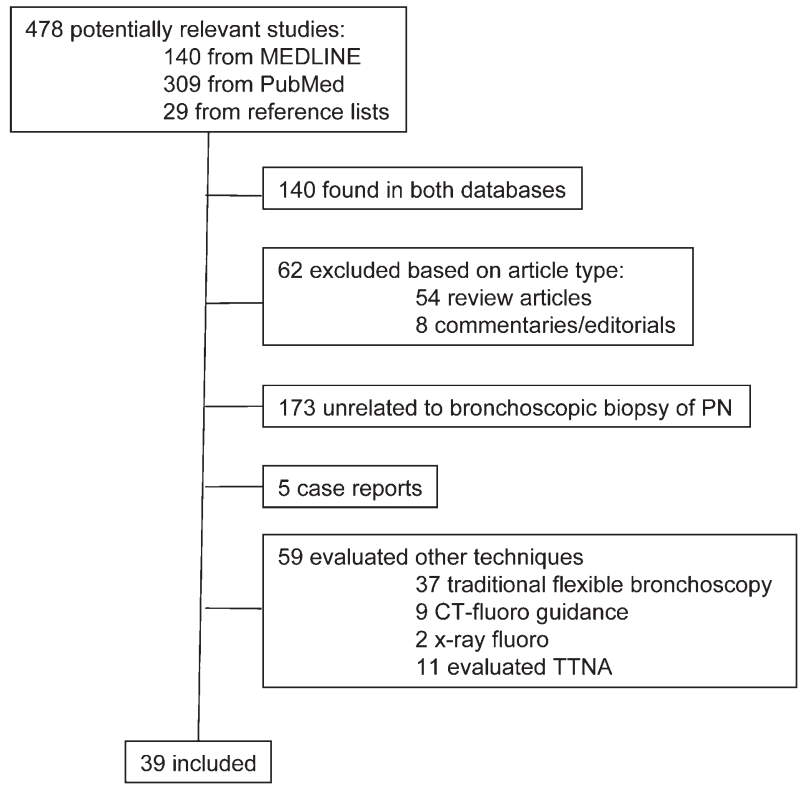

FIGURE 2. Literature search and selection. fluoro= fluoroscopy; $\mathrm{PN}=$ pulmonary nodule; TTNA = transthoracic needle aspiration.
Twenty-two studies evaluated the effect of size on the diagnostic yield (Table 3). Of these, 20 studies reported the diagnostic yields for lesions $\leq 20 \mathrm{~mm}$ and $>20 \mathrm{~mm}$ (in two studies, $30 \mathrm{~mm}$ was used as the size criteria, and those were excluded from this subanalysis). From these, the weighted diagnostic yields of the 629 lesions $\leq 20 \mathrm{~mm}$ and the 767 lesions $>20 \mathrm{~mm}$ were $60.9 \%$ (95\% CI, $54.0 \%$ to $67.7 \%$ ) and $82.5 \%$ (95\% CI, $78.6 \%$ to $86.4 \%$ ), respectively. The weighted difference in diagnostic yield for these two measurement groups is $19.6 \%$ (95\% CI, $11.7 \%$ to $27.6 \%$; $P<.001)$.

Of the studies included in the meta-analysis, 28 $(2,156$ total patients) reported on the rate of adverse events. The overall adverse event rate from those reported is $1.5 \%(\mathrm{n}=33)$ with the majority reporting pneumothorax. Thirty-two patients $(1.5 \%)$ developed a pneumothorax (range $0.0 \%$ to $7.5 \%$ across studies) and, of these, $14(0.6 \%)$ required placement of a chest tube and one underwent aspiration without placement of a chest tube. One patient $(0.1 \%)$ developed respiratory failure requiring intubation. No episodes of significant bleeding or death were reported.

\section{DISCUSSION}

This study has several important findings that may influence our current practice and approach to the evaluation and management of PN. First, the pooled diagnostic yield of $70 \%$ is much higher than yields reported previously using traditional bronchoscopic techniques. ${ }^{5,6}$ Second, although the diagnostic yield for guided bronchoscopic techniques is lower than that reported for TTNA, the adverse event rate is also significantly lower. Third, the yield is dependent on the size of the lesion. Finally, the use of VB, R-EBUS, and a guide sheath may have a greater influence on the diagnostic yield of bronchoscopic evaluation of PN.

The current algorithms for management of PN rely heavily on TTNA when a pathologic diagnosis is desired.,48 TTNA does have a 90\% chance of confirming a diagnosis (range, $76 \%$ to $90 \%$ ), but some report a pneumothorax rate as high as $40 \% .^{4,5,49-57}$ Additionally, the diagnostic yield is influenced by the size of the lesion, the size of the needle, the number of passes, and the presence of rapid on-site evaluation., $4,553-56$ The location of the lesion in the lungs, peripheral vs central, may also influence the diagnostic yield of TTNA.

In contrast, the sensitivity of the traditional bronchoscopic biopsy is only $34 \%$ for nodules $\leq 2 \mathrm{~cm}$, and has been found to be as low as $14 \% .^{5,6}$ The sensitivity increases to $63 \%$ when nodules are $>2 \mathrm{~cm}$ in size, but decreases as the distance from the hilum increases. A lesion having a bronchus sign (the finding of a bronchus leading to the lesion) increases the success of transbronchial biopsy and brushing. ${ }^{58}$ Recently, technology 
Table 1-List of Studies and Results Included in Meta-analysis

\begin{tabular}{|c|c|c|c|c|c|c|c|c|}
\hline No. & Study & Year & Pro/Retro & Technology & No. Lesions & No. Diagnosed & Yield, \% & Adverse \\
\hline 1 & Herth et al $^{9}$ & 2002 & Pro & R-EBUS & 50 & 40 & 80 & 1 PTX (1 CTI) \\
\hline 2 & Shirakawa et al ${ }^{10}$ & 2004 & Pro & R-EBUS, GS & 51 & 42 & 82.4 & No report \\
\hline 3 & Yang et all1 & 2004 & Retro & R-EBUS & 122 & 80 & 65.6 & None \\
\hline 4 & Shinagawa et al ${ }^{12}$ & 2004 & Pro & $\mathrm{U}, \mathrm{VB}$ & 26 & 17 & 65.4 & No report \\
\hline 5 & Yamamoto et $\mathrm{al}^{13}$ & 2004 & Pro & $\mathrm{U}$ & 35 & 21 & 60 & No report \\
\hline 6 & Kikuchi et al ${ }^{14}$ & 2004 & Pro & R-EBUS, GS & 24 & 14 & 58.3 & 1 PTX (1 CTI) \\
\hline 7 & Kurimoto et al 15 & 2004 & Pro & R-EBUS, GS & 150 & 116 & 77.3 & None \\
\hline 8 & Becker et al ${ }^{16}$ & 2005 & Pro & R-EBUS, ENB & 29 & 20 & 68.9 & 1 PTX (1 CTI) \\
\hline 9 & Hautmann et $\mathrm{al}^{17}$ & 2005 & Pro & ENB & 5 & 3 & 60 & None \\
\hline 10 & Asahina et al ${ }^{18}$ & 2005 & Pro & $\mathrm{U}, \mathrm{VB}, \mathrm{R}-\mathrm{EBUS}, \mathrm{GS}$ & 30 & 19 & 63.3 & None \\
\hline 11 & Paone et al ${ }^{19}$ & 2005 & Pro & R-EBUS & 87 & 66 & 75.8 & None \\
\hline 12 & Herth et al ${ }^{20}$ & 2006 & Pro & R-EBUS, GS & 54 & 38 & 70.4 & 1 PTX (1 CTI) \\
\hline 13 & Schwarz et al ${ }^{21}$ & 2006 & Pro & ENB & 13 & 9 & 69.2 & None \\
\hline 14 & Gildea et $\mathrm{al}^{22}$ & 2006 & Pro & ENB & 54 & 40 & 74.1 & 2 PTX (2 CTI) \\
\hline 15 & Asano et $\mathrm{al}^{23}$ & 2006 & Pro & $\mathrm{U}, \mathrm{VB}$ & 38 & 31 & 81.6 & No report \\
\hline 16 & Shinagawa et $\mathrm{al}^{24}$ & 2007 & Pro & $\mathrm{U}, \mathrm{VB}$ & 71 & 50 & 70.4 & No report \\
\hline 17 & Shinagawa et $\mathrm{al}^{25}$ & 2007 & Pro & $\mathrm{U}, \mathrm{VB}$ & 85 & 56 & 65.9 & No report \\
\hline 18 & Dooms et $\mathrm{al}^{26}$ & 2007 & Pro & R-EBUS & 50 & 34 & 68 & None \\
\hline 19 & Makris et $\mathrm{al}^{27}$ & 2007 & Pro & ENB & 40 & 25 & 62.5 & 3 PTX (1 CTI) \\
\hline 20 & Eberhardt et al ${ }^{28}$ & 2007 & Pro & R-EBUS, ENB, GS & 118 & 85 & 72 & 7 PTX (4 CTI, 1 aspiration) \\
\hline 21 & Tachihara et $\mathrm{al}^{29}$ & 2007 & Pro & $\mathrm{U}, \mathrm{VB}$ & 96 & 60 & 62.5 & None \\
\hline 22 & Yoshikawa et $\mathrm{al}^{30}$ & 2007 & Pro & R-EBUS, GS & 123 & 106 & 86.2 & 1 PTX (0 CTI) \\
\hline 23 & Eberhardt et al ${ }^{31}$ & 2007 & Pro & ENB & 92 & 62 & 67.4 & 2 PTX (0 CTI), 1 intub \\
\hline 24 & Yamada et al ${ }^{32}$ & 2007 & Retro & R-EBUS, GS & 158 & 106 & 67.1 & No report \\
\hline 25 & Wilson et $\mathrm{al}^{33}$ & 2007 & Retro & ENB & 279 & 167 & 59.9 & 3 PTX (0 CTI) \\
\hline 26 & Asano et $\mathrm{al}^{34}$ & 2008 & Pro & $\mathrm{U}, \mathrm{VB}, \mathrm{R}-\mathrm{EBUS}, \mathrm{GS}$ & 32 & 27 & 84.4 & No report \\
\hline 27 & Fielding et $\mathrm{al}^{35}$ & 2008 & Pro & R-EBUS, GS & 140 & 93 & 66.4 & 2 PTX (0 CTI) \\
\hline 28 & Oki et $\mathrm{al}^{36}$ & 2008 & Pro & $\mathrm{U}$ & 98 & 68 & 69.4 & None \\
\hline 29 & Lamprecht et $\mathrm{al}^{37}$ & 2009 & Retro & ENB & 13 & 10 & 76.9 & None \\
\hline 30 & Huang et $\mathrm{al}^{38}$ & 2009 & Retro & R-EBUS & 83 & 44 & 53 & 2 PTX (0 CTI) \\
\hline 31 & Weiner et $\mathrm{al}^{39}$ & 2009 & Pro & $\mathrm{VB}$ & 50 & 29 & 58 & No report \\
\hline 32 & Eberhardt et al ${ }^{40}$ & 2009 & Pro & R-EBUS, GS & 100 & 46 & 46 & 3 PTX (2 CTI) \\
\hline 33 & Bertoletti et al ${ }^{41}$ & 2009 & Pro & ENB & 53 & 41 & 77.3 & 2 PTX (1 CTI) \\
\hline 34 & Chao et al ${ }^{42}$ & 2009 & Pro & R-EBUS & 182 & 126 & 69.2 & No report \\
\hline 35 & Oki et $\mathrm{al}^{43}$ & 2009 & Pro & U, R-EBUS & 71 & 49 & 69 & None \\
\hline 36 & Iwano et al ${ }^{44}$ & 2011 & Retro & $\mathrm{VB}$ & 122 & 96 & 78.7 & No report \\
\hline 37 & Seijo et al ${ }^{45}$ & 2010 & Pro & ENB & 51 & 34 & 66.7 & None \\
\hline 38 & Disayabutr et al ${ }^{46}$ & 2010 & Pro & R-EBUS & 152 & 101 & 66.4 & None \\
\hline 39 & Eberhardt et al ${ }^{47}$ & 2010 & Pro & $\mathrm{U}, \mathrm{VB}$ & 25 & 20 & 80 & 1 PTX (0 CTI) \\
\hline
\end{tabular}

$\mathrm{CTI}=$ chest tube insertion; $\mathrm{ENB}=$ electromagnetic navigation bronchoscopy; GS = guide sheath; intub = intubation; pro = prospective; $\mathrm{PTX}=$ pneumothorax; R-EBUS = radial endobronchial ultrasound; retro = retrospective; $\mathrm{U}=$ ultrathin bronchoscope; VB $=$ virtual bronchoscopy.

has advanced to allow for better visualization of more distal airways with ultrathin bronchoscopes and endobronchial ultrasound. Additionally, virtual re-creation of the airway leading to the peripheral lesions, and navigation using improved CT imaging combined with $\mathrm{ENB}$ and $\mathrm{VB}$, allows for direction and guidance to those PN. With the advancement of these new modalities, the recommendations for diagnosing a PN allow for the use of bronchoscopy if newer guidance techniques are available. ${ }^{4}$ Few data, though, exist to determine if guided bronchoscopy is equivalent to TTNA or if these procedures are complementary, depending on the location of the target lesion and an assessment of patient risk.

This meta-analysis includes $>3,000$ cases of guided bronchoscopy performed for the diagnosis of PN. It establishes that the weighted diagnostic yield is significantly better than that reported for traditional flexible bronchoscopy, but the yield still remains lower than that of TTNA. ${ }^{4}$ Several studies included reported yields that approached the $90 \%$ yield of TTNA. Most notably, the study with the highest diagnostic yield using guided bronchoscopy compared a single method to a combination of technologies. Eberhardt et al28 studied ENB alone, R-EBUS alone, and ENB combined with R-EBUS. The diagnostic yields of ENB, R-EBUS, and the combination of the two were $59 \%$, $69 \%$, and $88 \%$, respectively. Although R-EBUS alone was better than ENB alone, the combination increased the yield to levels comparable to that of TTNA, suggesting that a combination of modalities may improve diagnostic yield.

Our results show wide variation in diagnostic yields among studies, which may be due to the differences 


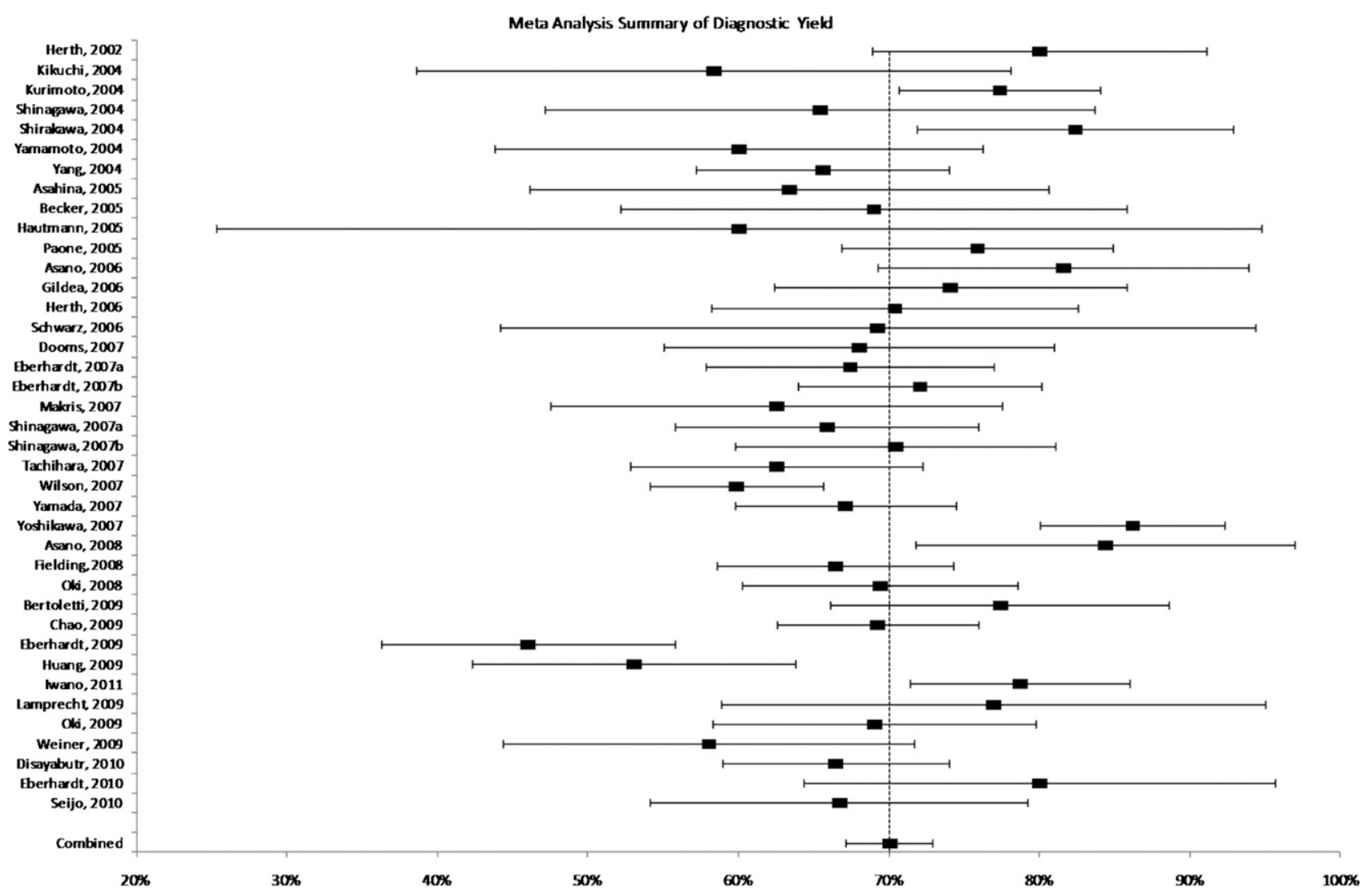

FIGURE 3. Overall summary of the diagnostic yields of the studies included in this meta-analysis.

in the definition of $\mathrm{PN}$; the variability in the location of lesions targeted, which affects biopsy method; and the many options for obtaining a biopsy specimen, which have varying yields and risks. Patient selection was not uniform: Some defined the PN as a wellcircumscribed opacity of $\leq 3 \mathrm{~cm}$ surrounded by aerated lung, whereas others defined it as a nodule farther than the fourth- or fifth-generation bronchi. The location of the lesion may also affect the ability to reach the lesion, but the location of the PN is not reported in all studies. Additionally, the various techniques used and operator ability can affect yield.

In this meta-analysis, three modalities had a higher diagnostic yield than the overall yield: VB, R-EBUS, and the use of a guide sheath. With R-EBUS, the location of the bronchoscope at the lesion can be verified with real-time visualization, and the guide sheath acts as an extended working channel to maintain that location during biopsy. Using these two technologies may help ensure that the lesion is definitively reached for biopsy. The finding of a higher weighted diagnostic yield with VB is more interesting, especially because it had a higher yield than ENB (Table 2). $\mathrm{ENB}$ has a VB component that is simulated prior to the bronchoscopy. In addition, ENB has real-time navigation that subsequently directs the bronchoscopist to the lesion, potentially making it more accurate.
However, the yield of ENB in this meta-analysis was less than that of VB alone. This may have depended on the software that generated the virtual picture, as well as on the operator.

Further subanalysis of the patients included in this meta-analysis supports the previous finding that diagnostic yield increases as the size of the PN increases. ${ }^{6}$ Of the studies that reported the diagnostic yield categorized by size, the yield was significantly higher for larger lesions. We are unable to comment on the effect of location on diagnostic yield because so few studies reported the yield in relation to the lobar location of the PN.

Of the studies that included information on adverse events, the rates of pneumothorax, hemorrhage, and

Table 2-Inverse Weighted Diagnostic Yield Overall and by Modality

\begin{tabular}{|c|c|c|c|c|c|}
\hline Technology & $\begin{array}{l}\text { Studies, } \\
\text { No. }\end{array}$ & $\begin{array}{c}\text { Weighted } \\
\text { Proportion, \% }\end{array}$ & $95 \%$ CI & Q Statistic & Q $P$ Value \\
\hline VB & 10 & 72.0 & $(65.7-78.4)$ & 21.0 & .01 \\
\hline ENB & 11 & .0 & $(62.6$ & 13.3 & .21 \\
\hline GS & 10 & 73.2 & $(64.4-81.9)$ & 63.8 & $<.0001$ \\
\hline $\mathrm{U}$ & 11 & 70.0 & (65.0 & 15.2 & .12 \\
\hline R-EBUS & 20 & 71.1 & $(66.5-75.7)$ & 84.2 & $<.0001$ \\
\hline All & 39 & 70.0 & $(67.1-72.9)$ & 119.4 & $<.0001$ \\
\hline
\end{tabular}

See Table 1 legend for expansion of abbreviations. 
Table 3-Studies That Reported on Diagnostic Yield Based on Size

\begin{tabular}{|c|c|c|c|c|c|c|c|}
\hline \multirow[b]{2}{*}{ No. } & \multirow[b]{2}{*}{ Study/Year } & \multicolumn{3}{|c|}{ Lesions $>20 \mathrm{~mm}$} & \multicolumn{3}{|c|}{ Lesions $\leq 20 \mathrm{~mm}$} \\
\hline & & Lesions, No. & Diagnoses Made, No. & Yield, \% & Lesions, No. & Diagnoses Made, No. & Yield, \% \\
\hline 1 & Kikuchi et al ${ }^{14} / 2004$ & 9 & 6 & 66.7 & 15 & 8 & 53.3 \\
\hline 2 & Kurimoto et al $15 / 2004$ & 69 & 57 & 82.6 & 81 & 59 & 72.8 \\
\hline 3 & Asahina et al ${ }^{18} / 2005$ & 12 & 11 & 91.7 & 18 & 8 & 44.4 \\
\hline 4 & Schwarz et al21/2006 & 11 & 8 & 72.7 & 2 & 1 & 50 \\
\hline 5 & Gildea et al²/2006 & 23 & 17 & 73.9 & 31 & 23 & 74.1 \\
\hline 6 & Asano et al23/2006 & 12 & 10 & 83.3 & 26 & 21 & 80.8 \\
\hline 7 & Dooms et al26/2007 & 39 & 32 & 82.1 & 11 & 2 & 18.2 \\
\hline 8 & Makris et al27/2007 & 20 & 15 & 75 & 20 & 10 & 50 \\
\hline 9 & Eberhardt et al28/2007 & 30 & 20 & 66.7 & 9 & 7 & 77.8 \\
\hline 10 & Tachihara et al29/2007 & 19 & 18 & 94.7 & 77 & 42 & 54.5 \\
\hline 11 & Yoshikawa et al ${ }^{30} / 2007$ & 86 & 78 & 90.7 & 37 & 28 & 75.7 \\
\hline 12 & Eberhardt et al ${ }^{31} / 2007$ & 57 & 40 & 70.2 & 35 & 22 & 62.9 \\
\hline 13 & Yamada et al ${ }^{32} / 2007$ & 84 & 65 & 77.4 & 74 & 41 & 55.4 \\
\hline 14 & Asano et al ${ }^{34} / 2008$ & 17 & 16 & 94.1 & 15 & 11 & 73.3 \\
\hline 15 & Oki et $\mathrm{al}^{36} / 2008$ & 75 & 55 & 73.3 & 23 & 13 & 56.5 \\
\hline 16 & Lamprecht et al ${ }^{37 / 2009}$ & 9 & 7 & 77.8 & 4 & 3 & 75 \\
\hline 17 & Eberhardt et al ${ }^{40 / 2009}$ & 0 & 0 & & 100 & 46 & 46 \\
\hline 18 & Bertoletti et al"1/2009 & 46 & 37 & 80.4 & 7 & 3 & 42.9 \\
\hline 19 & Oki et al ${ }^{43} / 2009$ & 57 & 44 & 77.2 & 14 & 5 & 35.7 \\
\hline 20 & Iwano et $\mathrm{al}^{44 / 2011}$ & 92 & 74 & 80.4 & 30 & 22 & 73.3 \\
\hline
\end{tabular}

respiratory failure were very low. Most of the patients who suffered an adverse event had a pneumothorax, but fewer than one-half of those needed management with a chest tube. One other patient developed respiratory failure requiring intubation and mechanical ventilation. Thus, the adverse event rate that required intervention was only $0.7 \%$. When compared with the $25 \%$ pneumothorax rate and an overall $5 \%$ chest tube rate with TTNA, the pneumothorax $(1.5 \%)$ and chest tube $(0.6 \%)$ rates with guided bronchoscopy were significantly lower. ${ }^{4}$

This meta-analysis does not give clear evidence that guided bronchoscopy is an adequate alternative to TTNA in all cases in which a diagnosis of PN is needed. It does show that using guidance when evaluating a PN will increase the yield of bronchoscopy, as will biopsy of lesions $>20 \mathrm{~mm}$. Because patient selection varies for those referred for TTNA compared with those referred for evaluation by bronchoscopy, the diagnostic yield and the adverse event rate of guided bronchoscopy needs to be prospectively compared with those of TTNA. A multicenter, prospective, randomized control trial would provide a direct comparison between guided bronchoscopy and TTNA, which may allow us to determine the most advantageous use of these guided biopsy modalities. As we continue to understand these new technologies better, including their limitations, we may find that the various options to reach and biopsy PN are complementary; the decision may be based on location (center vs periphery), size, and expertise available. Further study may help to determine the appropriate role of these emerging technologies.

\section{ConCLusions}

In summary, this meta-analysis, based on 39 studies with $>3,000$ patients spanning the past decade, shows that guided bronchoscopy for evaluation of $\mathrm{PN}$ provides a reasonably high diagnostic yield with a low side-effect profile. The release of the NLST findings and the continued interest in radiographic lung cancer screening will likely lead to an increase in the number of PN identified. As the current modalities evolve and new technologies are developed, the capability of bronchoscopy to reach peripheral PN for diagnostic and treatment purposes will continue to improve. It has become increasingly important to determine the role of these guided procedures in the evaluation of patients, with the goal of these emerging techniques to be to identify malignancy quickly while limiting risk to the patient.

\section{ACKNOWLEDGMENTS}

Author contributions: Dr Wang Memoli: contributed to the study concept and design, analysis and interpretation of the data, and drafting of the manuscript.

Dr Nietert: contributed to the analysis and interpretation of the data, and drafting of the manuscript.

Dr Silvestri: contributed to the study concept and design, analysis and interpretation of the data, and drafting of the manuscript.

Financial/nonfinancial disclosures: The authors have reported to CHEST the following conflicts of interest: Dr Nietert is a consultant to BioSystems International, providing statistical guidance on research studies. Dr Silvestri is the recipient of a research grant from the Olympus Corporation, has served as a consultant to Broncus, and has funding from a National Institutes of Health, National Cancer Institute midNIH NCI K24 career investigator mentor award (NIH NCI K24) in patient-oriented research. Dr Wang Memoli has reported that no potential conflicts of 
interest exist with any companies/organizations whose products or services may be discussed in this article.

Role of sponsors: The contents of this article are solely the responsibility of the authors and do not necessarily represent the official views of the National Institutes of Health or the National Center for Research Resources. The sponsors had no role in the design of the study, the collection and analysis of the data, or in the preparation of the manuscript.

\section{REFERENCES}

1. Stern SH. Nationwide Evaluation of X-ray Trends (NEXT): Tabulation and Graphical Summary of 2000 Survey of Computed Tomography. Frankfort, KY: Conference of Radiation Control Program Directors, Inc; 2007.

2. Aberle DR, Adams AM, Berg CD, et al; National Lung Screening Trial Research Team. Reduced lung-cancer mortality with low-dose computed tomographic screening. $N$ Engl J Med. 2011;365(5):395-409.

3. Wahidi MM, Govert JA, Goudar RK, Gould MK, McCrory DC; American College of Chest Physicians. Evidence for the treatment of patients with pulmonary nodules: when is it lung cancer? ACCP evidence-based clinical practice guidelines (2nd edition). Chest. 2007;132(suppl 3):94S-107S.

4. Gould MK, Fletcher J, Iannettoni MD, et al; American College of Chest Physicians. Evaluation of patients with pulmonary nodules: when is it lung cancer? ACCP evidence-based clinical practice guidelines (2nd edition). Chest. 2007;132(suppl 3): 108S-130S.

5. Rivera MP, Mehta AC; American College of Chest Physicians. Initial diagnosis of lung cancer: ACCP evidence-based clinical practice guidelines (2nd edition). Chest. 2007;132(suppl 3): 131S-148S.

6. Baaklini WA, Reinoso MA, Gorin AB, Sharafkaneh A, Manian P. Diagnostic yield of fiberoptic bronchoscopy in evaluating solitary pulmonary nodules. Chest. 2000;117(4):1049-1054.

7. Hedges LV, Olkin I. Statistical Methods for Meta-analysis. Orlando, FL: Academic Press; 1985.

8. Casella G, Berger RL. Statistical Inference. 2nd ed. Pacific Grove, CA: Duxbury Advanced Series; 2002.

9. Herth FJ, Ernst A, Becker HD. Endobronchial ultrasoundguided transbronchial lung biopsy in solitary pulmonary nodules and peripheral lesions. Eur Respir J. 2002;20(4):972-974.

10. Shirakawa T, Imamura F, Hamamoto J, et al. Usefulness of endobronchial ultrasonography for transbronchial lung biopsies of peripheral lung lesions. Respiration. 2004;71(3):260-268.

11. Yang MC, Liu WT, Wang CH, et al. Diagnostic value of endobronchial ultrasound-guided transbronchial lung biopsy in peripheral lung cancers. J Formos Med Assoc. 2004;103(2): 124-129.

12. Shinagawa N, Yamazaki K, Onodera Y, et al. CT-guided transbronchial biopsy using an ultrathin bronchoscope with virtual bronchoscopic navigation. Chest. 2004;125(3):1138-1143.

13. Yamamoto S, Ueno K, Imamura F, et al. Usefulness of ultrathin bronchoscopy in diagnosis of lung cancer. Lung Cancer. 2004;46(1):43-48.

14. Kikuchi E, Yamazaki K, Sukoh N, et al. Endobronchial ultrasonography with guide-sheath for peripheral pulmonary lesions. Eur Respir J. 2004;24(4):533-537.

15. Kurimoto N, Miyazawa T, Okimasa S, et al. Endobronchial ultrasonography using a guide sheath increases the ability to diagnose peripheral pulmonary lesions endoscopically. Chest. 2004;126(3):959-965.

16. Becker HC, Herth F, Ernst A. Bronchoscopic biopsy of peripheral lung lesions under electromagnetic guidance: a pilot study. J Bronchol. 2005;12:9-13.

17. Hautmann H, Schneider A, Pinkau T, Peltz F, Feussner H. Electromagnetic catheter navigation during bronchoscopy: validation of a novel method by conventional fluoroscopy. Chest. 2005;128(1):382-387.

18. Asahina H, Yamazaki K, Onodera Y, et al. Transbronchial biopsy using endobronchial ultrasonography with a guide sheath and virtual bronchoscopic navigation. Chest. 2005; 128(3):1761-1765.

19. Paone G, Nicastri E, Lucantoni G, et al. Endobronchial ultrasound-driven biopsy in the diagnosis of peripheral lung lesions. Chest. 2005;128(5):3551-3557.

20. Herth FJ, Eberhardt R, Becker HD, Ernst A. Endobronchial ultrasound-guided transbronchial lung biopsy in fluoroscopically invisible solitary pulmonary nodules: a prospective trial. Chest. 2006;129(1):147-150.

21. Schwarz Y, Greif J, Becker HD, Ernst A, Mehta A. Real-time electromagnetic navigation bronchoscopy to peripheral lung lesions using overlaid CT images: the first human study. Chest. 2006;129(4):988-994

22. Gildea TR, Mazzone PJ, Karnak D, Meziane M, Mehta AC. Electromagnetic navigation diagnostic bronchoscopy: a prospective study. Am J Respir Crit Care Med. 2006;174(9): 982-989.

23. Asano F, Matsuno Y, Shinagawa N, et al. A virtual bronchoscopic navigation system for pulmonary peripheral lesions. Chest. 2006;130(2):559-566

24. Shinagawa N, Yamazaki K, Onodera Y, et al. Virtual bronchoscopic navigation system shortens the examination timefeasibility study of virtual bronchoscopic navigation system. Lung Cancer. 2007;56(2):201-206.

25. Shinagawa N, Yamazaki K, Onodera Y, et al. Factors related to diagnostic sensitivity using an ultrathin bronchoscope under CT guidance. Chest. 2007;131(2):549-553.

26. Dooms CA, Verbeken EK, Becker HD, Demedts MG, Vansteenkiste JF. Endobronchial ultrasonography in bronchoscopic occult pulmonary lesions. J Thorac Oncol. 2007;2(2): 121-124.

27. Makris D, Scherpereel A, Leroy S, et al. Electromagnetic navigation diagnostic bronchoscopy for small peripheral lung lesions. Eur Respir J. 2007;29(6):1187-1192.

28. Eberhardt R, Anantham D, Ernst A, Feller-Kopman D, Herth F. Multimodality bronchoscopic diagnosis of peripheral lung lesions: a randomized controlled trial. Am J Respir Crit Care Med. 2007;176(1):36-41.

29. Tachihara M, Ishida T, Kanazawa K, et al. A virtual bronchoscopic navigation system under X-ray fluoroscopy for transbronchial diagnosis of small peripheral pulmonary lesions. Lung Cancer. 2007;57(3):322-327.

30. Yoshikawa M, Sukoh N, Yamazaki K, et al. Diagnostic value of endobronchial ultrasonography with a guide sheath for peripheral pulmonary lesions without X-ray fluoroscopy. Chest. 2007;131(6):1788-1793.

31. Eberhardt R, Anantham D, Herth F, Feller-Kopman D, Ernst A. Electromagnetic navigation diagnostic bronchoscopy in peripheral lung lesions. Chest. 2007;131(6):1800-1805.

32. Yamada N, Yamazaki K, Kurimoto N, et al. Factors related to diagnostic yield of transbronchial biopsy using endobronchial ultrasonography with a guide sheath in small peripheral pulmonary lesions. Chest. 2007;132(2):603-608.

33. Wilson DS, Bartlett RJ. Improved diagnostic yield of bronchoscopy in a community practice: combination of electromagnetic navigation system and rapid on-site evaluation. J Bronchol. 2007;14(4):227-232.

34. Asano F, Matsuno Y, Tsuzuku A, et al. Diagnosis of peripheral pulmonary lesions using a bronchoscope insertion guidance system combined with endobronchial ultrasonography with a guide sheath. Lung Cancer. 2008;60(3):366-373.

35. Fielding DI, Robinson PJ, Kurimoto N. Biopsy site selection for endobronchial ultrasound guide-sheath transbronchial 
biopsy of peripheral lung lesions. Intern Med J. 2008;38(2): 77-84.

36. Oki M, Saka H, Kitagawa C, et al. Novel thin bronchoscope with a $1.7-\mathrm{mm}$ working channel for peripheral pulmonary lesions. Eur Respir J. 2008;32(2):465-471.

37. Lamprecht B, Porsch P, Pirich C, Studnicka M. Electromagnetic navigation bronchoscopy in combination with PET-CT and rapid on-site cytopathologic examination for diagnosis of peripheral lung lesions. Lung. 2009;187(1): 55-59.

38. Huang CT, Ho CC, Tsai YJ, Yu CJ, Yang PC. Factors influencing visibility and diagnostic yield of transbronchial biopsy using endobronchial ultrasound in peripheral pulmonary lesions. Respirology. 2009;14(6):859-864.

39. Weiner GM, Schulze K, Geiger B, Ebhardt H, Wolf KJ, Albrecht T. CT bronchoscopic simulation for guiding transbronchial needle aspiration of extramural mediastinal and hilar lesions: initial clinical results. Radiology . 2009;250(3):923-931.

40. Eberhardt R, Ernst A, Herth FJ. Ultrasound-guided transbronchial biopsy of solitary pulmonary nodules less than 20 mm. Eur Respir J. 2009;34(6):1284-1287.

41. Bertoletti L, Robert A, Cottier M, Chambonniere ML, Vergnon JM. Accuracy and feasibility of electromagnetic navigated bronchoscopy under nitrous oxide sedation for pulmonary peripheral opacities: an outpatient study. Respiration. 2009; 78(3):293-300.

42. Chao TY, Chien MT, Lie CH, Chung YH, Wang JL, Lin MC. Endobronchial ultrasonography-guided transbronchial needle aspiration increases the diagnostic yield of peripheral pulmonary lesions: a randomized trial. Chest. 2009;136(1):229-236.

43. Oki M, Saka H, Kitagawa C, Kogure Y, Mori K, Kajikawa S. Endobronchial ultrasound-guided transbronchial biopsy using novel thin bronchoscope for diagnosis of peripheral pulmonary lesions. J Thorac Oncol. 2009;4(10):1274-1277.

44. Iwano S, Imaizumi K, Okada T, Hasegawa Y, Naganawa S. Virtual bronchoscopy-guided transbronchial biopsy for aiding the diagnosis of peripheral lung cancer. Eur J Radiol. 2011; 79(1):155-159.

45. Seijo LM, de Torres JP, Lozano MD, et al. Diagnostic yield of electromagnetic navigation bronchoscopy is highly dependent on the presence of a bronchus sign on CT imaging: results from a prospective study. Chest. 2010;138(6):1316-1321.

46. Disayabutr S, Tscheikuna J, Nana A. The endobronchial ultrasound-guided transbronchial lung biopsy in peripheral pulmonary lesions. J Med Assoc Thai. 2010;93(suppl 1):S94-S101.
47. Eberhardt R, Kahn N, Gompelmann D, Schumann M, Heussel CP, Herth FJ. LungPoint-a new approach to peripheral lesions. J Thorac Oncol. 2010;5(10):1559-1563.

48. Ost D, Fein AM, Feinsilver SH. Clinical practice. The solitary pulmonary nodule. $N$ Engl J Med. 2003;348(25):2535-2542.

49. Larscheid RC, Thorpe PE, Scott WJ. Percutaneous transthoracic needle aspiration biopsy: a comprehensive review of its current role in the diagnosis and treatment of lung tumors. Chest. 1998;114(3):704-709.

50. Loubeyre P, Copercini M, Dietrich PY. Percutaneous CTguided multisampling core needle biopsy of thoracic lesions. AJR Am J Roentgenol. 2005;185(5):1294-1298.

51. Santambrogio L, Nosotti M, Bellaviti N, Pavoni G, Radice F, Caputo V. CT-guided fine-needle aspiration cytology of solitary pulmonary nodules: a prospective, randomized study of immediate cytologic evaluation. Chest. 1997;112(2):423-425.

52. Schreiber G, McCrory DC. Performance characteristics of different modalities for diagnosis of suspected lung cancer: summary of published evidence. Chest. 2003;123(suppl 1): 115S-128S.

53. Cox JE, Chiles C, McManus CM, Aquino SL, Choplin RH. Transthoracic needle aspiration biopsy: variables that affect risk of pneumothorax. Radiology. 1999;212(1):165-168.

54. Ko JP, Shepard JO, Drucker EA, et al. Factors influencing pneumothorax rate at lung biopsy: are dwell time and angle of pleural puncture contributing factors? Radiology. 2001; 218(2):491-496

55. Covey AM, Gandhi R, Brody LA, Getrajdman G, Thaler HT, Brown KT. Factors associated with pneumothorax and pneumothorax requiring treatment after percutaneous lung biopsy in 443 consecutive patients. J Vasc Interv Radiol. 2004;15(5): 479-483.

56. Heyer CM, Reichelt S, Peters SA, Walther JW, Müller KM, Nicolas V. Computed tomography-navigated transthoracic core biopsy of pulmonary lesions: which factors affect diagnostic yield and complication rates? Acad Radiol. 2008;15(8): 1017-1026.

57. Wiener RS, Schwartz LM, Woloshin S, Welch HG. Populationbased risk for complications after transthoracic needle lung biopsy of a pulmonary nodule: an analysis of discharge records. Ann Intern Med. 2011;155(3):137-144.

58. Gaeta M, Pandolfo I, Volta S, et al. Bronchus sign on CT in peripheral carcinoma of the lung: value in predicting results of transbronchial biopsy. AJR Am J Roentgenol. 1991;157(6): 1181-1185. 